\title{
Infant and young child feeding practices and child undernutrition in Bangladesh: insights from nationally representative data
}

\author{
Amanda Zongrone ${ }^{1}$, Kate Winskell ${ }^{2}$ and Purnima Menon ${ }^{3, *}$ \\ 'Division of Nutritional Sciences, Cornell University, lthaca, NY, USA: ${ }^{2}$ Rollins School of Public Health, \\ Emory University, Atlanta, GA, USA: ${ }^{3}$ International Food Policy Research Institute, New Delhi Office, \\ CG Block, NASC Complex, DPS Road, New Delhi 110 012, India
}

Submitted 21 April 2011: Final revision received 21 November 2011: Accepted 24 February 2012: First published online 8 May 2012

\begin{abstract}
Objective: To determine the association between indicators of infant and young child feeding (IYCF) and anthropometric measures of nutritional status among children aged 0-23 months in a nationally representative data set.

Design: Data from the 2007 Bangladesh Demographic and Health Survey were used. Analyses were conducted using multiple linear regression and logistic regression analyses adjusted for the complex survey design of the survey, controlling for child, maternal and household characteristics, and including regional dummy variables.

Setting: Bangladesh.

Subjects: Pairs ( $n$ 2096) of last born infants and their mothers.

Results: Exclusive breast-feeding under 6 months of age was associated with higher weight-for-height $Z$-score (effect size $(\mathrm{ES})=0 \cdot 29 ; P<0 \cdot 05$ ). Appropriate complementary feeding in children aged $6-8$ months was associated with higher height-for-age $Z$-score (HAZ; ES $=0.63 ; P<0 \cdot 01$ ) and higher weight-for-age $Z$-score (WAZ; ES $=0.30 ; P<0 \cdot 05$ ). Higher dietary diversity index (DDI) was associated with higher $\mathrm{HAZ}(\mathrm{ES}=0 \cdot 08 ; P<0 \cdot 01$ for every 1 point higher DDI) and higher WAZ (ES $=0 \cdot 04 ; P<0 \cdot 05)$. Children who achieved minimum diet diversity had higher $\mathrm{HAZ}(\mathrm{ES}=0 \cdot 20 ; P<0 \cdot 05)$. Logistic regression models confirmed that exclusive breast-feeding was protective against wasting and DDI was protective against stunting and underweight.

Conclusions: Our results highlight the importance of IYCF practices as determinants of child growth outcomes in this context, and reinforce the need for interventions that address the spectrum of IYCF practices, from exclusive breast-feeding to age-appropriate complementary feeding, especially diet diversity, in efforts to improve nutrition of infants and young children.
\end{abstract}

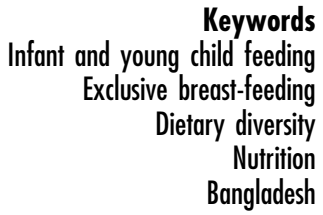

Globally, childhood undernutrition is one of the most important public health challenges. When considering all causes of under- $5 \mathrm{~s}$ mortality worldwide, it is estimated that $35 \%$ of these deaths are attributable to malnutrition ${ }^{(1)}$. The critical 'window of opportunity' for child growth is in the first 2 years of life; recent analyses have found that the effect of growth faltering during this period is more severe than previously thought ${ }^{(2)}$. In this critical period for the growth of children under 2 years of age, it is essential to ensure proper nutrition. According to the UNICEF conceptual framework for child nutrition ${ }^{(3)}$, both dietary intake and health care are critical determinants of child undernutrition.

Aspects of infant and young child feeding (IYCF) that are important in the first 2 years of life include: early initiation of breast-feeding; exclusive breast-feeding for the first 6 months of life; adequate, timely and appropriate complementary feeding from 6 to 24 months of age; continued breast-feeding after the introduction of complementary foods; adequate dietary diversity in complementary foods; and adequate frequency of meals. A large body of research was conducted over almost a decade, to hone in on the most critical IYCF practices and to derive globally accepted indicators for capturing the range and quality of these IYCF practices ${ }^{(4-9)}$. The WHO-recommended indicators of IYCF practices were an outcome of this process, and the currently recommended indicators include both core and optional indicators that can be used to measure these practices in population-based surveys ${ }^{(8)}$. 
Previous studies have investigated the relationship between IYCF practices and child growth. In a study using data from five countries in Latin America, a significant association was found between better child feeding practices (which included breast-feeding, appropriate use of complementary foods, feeding frequency and the diversity of the diet) and nutritional status among children 12-36 months of age ${ }^{(10)}$. That study established a young child feeding index that has subsequently been adapted to test the relationship between child feeding practices and child growth in multiple settings including rural Senegal ${ }^{(11)}$, Burkina Faso $^{(12)}$, rural India ${ }^{(13)}$, urban Madagascar ${ }^{(14)}$ and rural China ${ }^{(15)}$. One longitudinal study in Bangladesh constructed an infant feeding scale and found that children who scored higher on the infant feeding scale were more likely to have better growth later in infancy. Although that study was able to capture many of the core infant feeding practices outlined by the WHO in their scale, the relationship between food variety and child growth could not be evaluated due to lack of adequate data on foods fed to children ${ }^{(16)}$.

While these studies have used composite infant feeding scales and indices that captured many of the WHO-recommended IYCF practices, many other studies have focused only on the relationship between specific aspects of IYCF and child growth. For example, the association between breast-feeding practices and child growth has been investigated in a number of settings: Bangladesh $^{(17,18)}$, Malawi ${ }^{(19)}$, Brazil ${ }^{(20,21)}$, Columbia ${ }^{(22)}$, Turkey $^{(23)}$, rural Senegal ${ }^{(24)}$ and Mexico ${ }^{(25,26)}$. Additionally, the appropriate introduction of complementary foods (both timing and type) and associations with child growth have been studied in Malawi ${ }^{(19,27)}$, Vietnam ${ }^{(28)}$, Barbados $^{(29)}$ and Senegal ${ }^{(30)}$.

Another IYCF practice that has been well studied is dietary diversity, which is recognized as important in enabling children 6-24 months of age to achieve adequate nutrient density in their diet ${ }^{(31-36)}$. Previous studies have examined the association between dietary diversity and anthropometric measures of nutritional status in countries of Africa, South Asia, South-East Asia and Latin America/ Caribbean. Using Demographic and Health Survey (DHS) data from these regions, chronic undernutrition was found to be significantly associated with dietary diversity ${ }^{(37)}$. Significant and positive associations between dietary diversity and nutritional status among young children have also been found in smaller-scale studies in rural Bangladesh ${ }^{(38)}$, rural Burkina Faso ${ }^{(12)}$, Kenya ${ }^{(39)}$, Mexico ${ }^{(40)}$ and Mali ${ }^{(41)}$, and in a review in Africa ${ }^{(35)}$.

The relationships between the newly established WHOrecommended IYCF indicators with nutritional outcomes have not been previously examined using national-level data from Bangladesh. The present research applied the newly established indicators to nationally representative data, to study and illustrate the associations between IYCF practices and growth in Bangladeshi children.

\section{Materials and methods}

Survey data from the 2007 DHS in Bangladesh were used. The DHS is a nationally representative household survey that is available for public use ${ }^{(42)}$. Data from the children's re-coded data set, which contains one record for every child of eligible women who were born in the last 5 years (0-59 months of age), were adjusted for cluster sampling and sampling weights for the present analysis. Children who were not alive during the interview or had a missing age variable were dropped from the sample. Regression analysis included only the youngest child in each family as the DHS collected dietary diversity data only on this population. Data were analysed for children between the ages of 0 and 23 months who had corresponding data for the outcome variables of interest as well as the control variables. If data were missing for any of these variables, the child was not included. Additionally, children who had implausible corresponding maternal heights (less than $100 \mathrm{~cm}$ ) were not included in the analytic sample.

\section{Infant and young child feeding indicators}

The following IYCF indicators were calculated as specified by the WHO Indicators for Assessing Infant and Young Child Feeding Practices ${ }^{(8)}$, based on available data from the 2007 Bangladesh DHS: early initiation of breast-feeding; exclusive breast-feeding under 6 months of age; continued breast-feeding at 1 year of age; introduction of solid, semi-solid or soft foods; minimum dietary diversity; minimum meal frequency; minimum acceptable diet; and consumption of Fe-rich foods. The optional IYCF indicators of continued breast-feeding at 2 years of age, age-appropriate breast-feeding and predominant breast-feeding at less than 6 months of age were also calculated. All of these variables were calculated per the WHO guidelines except for minimum dietary diversity (described below), which had to be adapted because of a limitation with the data available for calculating the dietary diversity index.

\section{Dietary diversity index}

A dietary diversity index (DDI) was created, rating the diversity of a child's diet from 0 to 6 by giving one point for each of the following food groups that were consumed the previous day (during the daytime or at night): (i) grains, roots and tubers; (ii) legumes and nuts; (iii) dairy products; (iv) flesh foods and eggs; (v) vitamin-A rich fruits and vegetables; and (vi) other fruits and vegetables.

Although the currently recommended indicators for assessing IYCF practices ${ }^{(8)}$ recommend the use of seven categories (flesh foods and eggs are two separate categories), the 2007 Bangladesh DHS ${ }^{(42)}$ combines meat, fish and eggs into one question. Therefore, six categories were used for the present study. 


\section{Minimum dietary diversity}

Minimum dietary diversity (MDD) was defined in the present study as the proportion of children aged 6-23 months who received foods from four or more food groups (out of six). The recommended core indicator is four out of seven groups ${ }^{(8)}$; however, as discussed previously, only six groups were available for the present study.

\section{Antbropometric measures of nutritional status}

Anthropometric measures of nutritional status, namely height-for-age $Z$-score (HAZ), weight-for-age $Z$-score (WAZ) and weight-for-height Z-score (WHZ), were calculated based on the WHO growth standards and were used to determine nutritional status among the children ${ }^{(43)}$. Stunting, underweight and wasting were defined as being less than 2 sD below the median value for HAZ, WAZ and WHZ, respectively.

\section{Sociodemographic influences}

Variables included in the regression analyses were decided a priori based on potential influences on nutrition in the Bangladeshi context. These variables were: child sex, child age, the square of child age, maternal height, maternal BMI, maternal education, prenatal care visits, wealth index, current breast-feeding status, number of children, age of mother at first birth, residence (urban $v$. rural) and location (division in Bangladesh). In these analyses, child sex was defined as either male or female; child age was calculated using the number of days from the reported date of birth and then converted to months; maternal educational attainment (reported as none, primary, secondary or higher) was defined in two variables, (i) primary education $v$. no education and (ii) secondary education $v$. no education; and maternal height was given to the nearest $0 \cdot 1 \mathrm{~cm}$. The DHS calculates a wealth index using the DHS standard method based on ownership of assets, types of water access and sanitation facilities. Using principal components analysis to compute the wealth index, households in the data set are then classified into the poorest, poorer, middle, richer or richest wealth quintile based on the range of scores for Bangladesh $^{(44)}$. The index value given to each household was used in the present analysis.

\section{Analysis}

A multiple linear regression model was developed to determine the association between IYCF indicators and the continuous measures of anthropometric status (HAZ, WAZ and WHZ). Binomial logistic regression analysis was used to determine the association between the IYCF indicators and the binary outcomes of stunting, underweight and wasting. All regression models adjusted for the following potential confounding factors: child age in months, the square of child age, sex of the child, height of the mother, maternal BMI, education of the mother, prenatal care visits, urban $v$, rural residence, wealth index, current breast-feeding status, number of children, the age of the mother at first birth and regional dummy variables (division in Bangladesh) to control for unobservable factors at the regional level. When running the regression models for the IYCF indicators that were relevant only for currently breast-feeding children, current breast-feeding status was not used as a control variable. Regression models were run using the 'svy' command in STATA to ensure that standard errors were adjusted for the complex survey design. Adjusted mean HAZ was estimated using the 'margins' command in STATA, generating predicted HAZ values based on the corresponding regression model. The STATA statistical software package version 11 (2010; StataCorp LP, College Station, TX, USA) was used for all analyses.

\section{Results}

\section{Sample characteristics}

Table 1 and Fig. 1 describe the characteristics of the sample. Overall, child age was distributed as 6-11 months (29.91\%), 12-17 months (40.45\%) and 18-23 months (29.64\%), and gender was evenly split (50.60\% male and $49 \cdot 40 \%$ female).

In this sample $33.69 \%$ of children were stunted, $21 \cdot 42 \%$ were wasted and $34 \cdot 75 \%$ were underweight. The mean HAZ, WAZ and WHZ were $-1.45,-1.58$ and $-1 \cdot 13$, respectively (Table 1 ). The percentage of children in the sample meeting MDD was $45 \cdot 16 \%$ and the percentage of children who were exclusively breast-fed under 6 months was $36 \cdot 05 \%$ (Fig. 1).

\section{Regression results}

The results of the regression analyses that examined associations between the different IYCF indicators and anthropometric outcomes are summarized in Table 2. These models present the associations between adherence to the WHO-recommended IYCF practices and child anthropometry. The results in Table 2 demonstrate that exclusive breast-feeding under 6 months of age predicted WHZ higher by $0 \cdot 29(P=0 \cdot 049)$. For children with ageappropriate introduction of solid, semi-solid or soft foods, HAZ was higher by $0.63(P=0.005)$ and WAZ was higher by $0.30(P=0 \cdot 038)$. Additionally, the log of the odds of stunting was lower by $1.34(P=0 \cdot 005)$ for children with age-appropriate introduction of complementary foods. As DDI rose by 1 point, HAZ was higher by $0 \cdot 08(P=0 \cdot 006)$ and WAZ higher by $0.04(P=0.045)$. The $\log$ of the odds of stunting and underweight was lower by $0 \cdot 12$ $(P=0 \cdot 020)$ and $0 \cdot 12(P=0 \cdot 013)$, respectively, as DDI increased by 1 point. For a child who was consuming at least four out of six food groups and thus achieving MDD, HAZ was higher by $0 \cdot 20(P=0 \cdot 024)$. The summary IYCF indicator of minimum acceptable diet predicted HAZ 
Table 1 Characteristics of the sample ( $n$ 1508), 2007 Bangladesh Demographic and Health Survey

\begin{tabular}{|c|c|c|}
\hline & $\begin{array}{l}\text { Mean or } \\
\text { proportion }\end{array}$ & SE \\
\hline \multicolumn{3}{|l|}{ Child characteristics (6-23 months of age) } \\
\hline Male & $50 \cdot 60$ & \\
\hline $\mathrm{HAZ}+$ & $-1 \cdot 45$ & 0.04 \\
\hline WAZt & $-1 \cdot 58$ & 0.03 \\
\hline WHZt & $-1 \cdot 13$ & 0.03 \\
\hline Stunted (HAZ <-2) & $33 \cdot 69$ & \\
\hline Wasted $(\mathrm{WHZ}<-2)$ & $21 \cdot 42$ & \\
\hline Underweight (WAZ <-2) & $34 \cdot 75$ & \\
\hline \multicolumn{3}{|l|}{ Age (months) } \\
\hline $6-11$ & $29 \cdot 91$ & \\
\hline $12-17$ & $40 \cdot 45$ & \\
\hline $18-23$ & $29 \cdot 64$ & \\
\hline \multicolumn{3}{|l|}{ Dietary diversity index } \\
\hline 0 & $5 \cdot 31$ & \\
\hline 1 & $11 \cdot 21$ & \\
\hline 2 & $15 \cdot 05$ & \\
\hline 3 & $23 \cdot 28$ & \\
\hline 4 & $24 \cdot 34$ & \\
\hline 5 & $14 \cdot 52$ & \\
\hline 6 & $6 \cdot 30$ & \\
\hline Achieved minimum dietary diversity & $45 \cdot 16$ & \\
\hline Currently breast-feeding & $95 \cdot 23$ & \\
\hline Consumption of Fe-rich food & $51 \cdot 46$ & \\
\hline \multicolumn{3}{|l|}{ Maternal characteristics } \\
\hline Heightt $(\mathrm{cm})$ & $150 \cdot 72$ & $0 \cdot 14$ \\
\hline \multicolumn{3}{|l|}{ Highest education level } \\
\hline None & $22 \cdot 81$ & \\
\hline Primary & $30 \cdot 37$ & \\
\hline Secondary & $37 \cdot 73$ & \\
\hline Higher & $9 \cdot 08$ & \\
\hline \multicolumn{3}{|l|}{ Wealth index } \\
\hline Poorest & $18 \cdot 50$ & \\
\hline Poorer & $19 \cdot 36$ & \\
\hline Middle & $19 \cdot 43$ & \\
\hline Richer & $18 \cdot 24$ & \\
\hline Richest & $24 \cdot 47$ & \\
\hline \multicolumn{3}{|l|}{ Location } \\
\hline Barisal & $11 \cdot 60$ & \\
\hline Chittagong & $21 \cdot 35$ & \\
\hline Dhaka & $22 \cdot 55$ & \\
\hline Khulna & 11.94 & \\
\hline Rajshahi & $17 \cdot 57$ & \\
\hline Sylhet & $14 \cdot 99$ & \\
\hline
\end{tabular}

HAZ, height-for-age Z-score; WAZ, weight-for-age Z-score; WHZ, weightfor-height $Z$-score.

tValues are presented as means with their standard errors. higher by $0 \cdot 19(P=0 \cdot 024)$ for those children who had a minimum acceptable diet. An illustrative example of a full regression model is provided in Table 3 which depicts the linear regression results for the association between DDI and HAZ.

The adjusted mean HAZ was significantly higher $(P=0 \cdot 024)$ for children aged 6-23 months who achieved MDD compared with those who did not (Fig. 2). Adjusted mean WAZ was marginally higher $(P=0 \cdot 11)$ among those who achieved MDD; mean WHZ $(P=0.97)$ was not significantly associated with MDD.

\section{Discussion}

Using nationally representative data from Bangladesh, the analyses reported herein established a significant, positive linear association between a variety of IYCF practices and child HAZ. Specifically, exclusive breast-feeding among children under 6 months of age was significantly and positively associated with WHZ, but not with other anthropometric outcomes in this age group. We also found that age-appropriate introduction of solid, semi-solid and soft foods, a better DDI, achieving MDD and a minimum acceptable diet were associated with better HAZ. Additionally, a significant, positive linear association was found between age-appropriate introduction of solid, semi-solid and soft foods and better dietary diversity and WAZ.

The analyses indicated that exclusive breast-feeding was protective against wasting among children 0-6 months of age; this complements existing evidence that exclusive breast-feeding protects against infectious diseases, through both broad immune system benefits and the reduction in exposure to contaminated food ${ }^{(45,46)}$. Additionally, this finding is consistent with evidence that exclusive breast-feeding has a positive relationship with length and weight gain among infants in developing countries $^{(47)}$. Given the high levels of early wasting among infants in Bangladesh ${ }^{(42)}$ and other South Asian countries $^{(48)}$, the finding that exclusive breast-feeding is

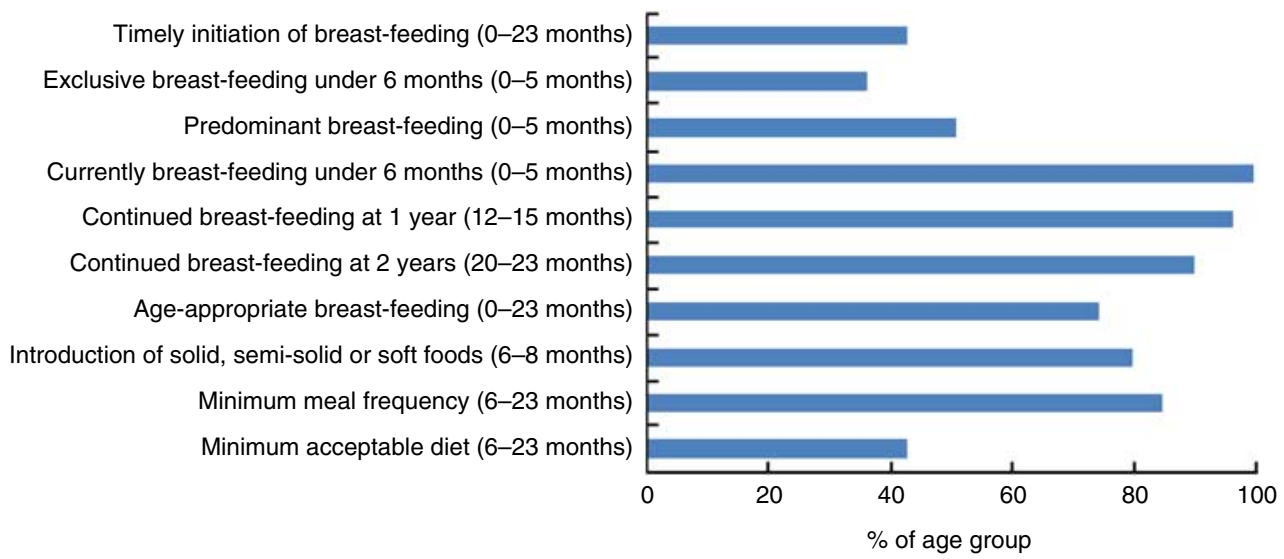

Fig. 1 (colour online) Infant and young child feeding practices among children aged 0-23.9 months, 2007 Bangladesh Demographic and Health Survey 


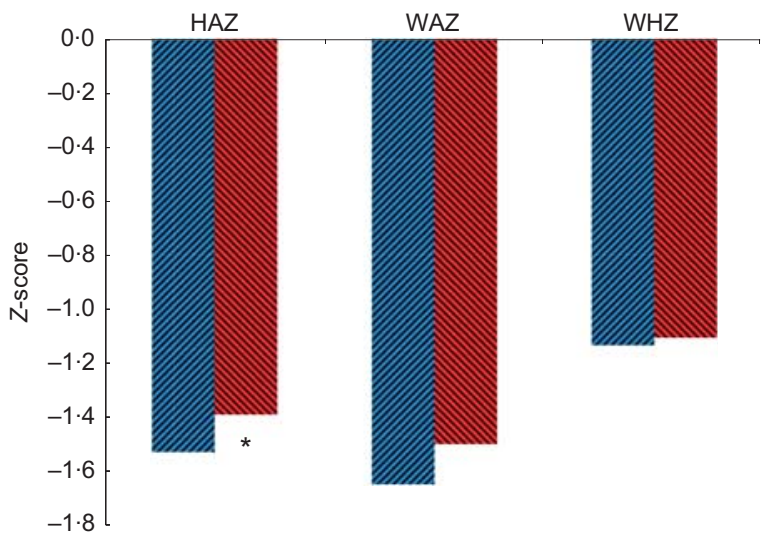

Fig. 2 (colour online) Adjusted mean height-for-age Z-score (HAZ), weight-for-age Z-score (WAZ) and weight-for-height Z-score (WHZ) by achievement of minimum dietary diversity (MDD; , did not achieve MDD; $\square$, achieved MDD) among children aged 6-23 months, 2007 Bangladesh Demographic and Health Survey. Mean values were significantly different from those who did not achieve MDD: ${ }^{\star} P<0.05$

protective against wasting is important from a public health and public policy perspective for the region. The lack of finding an association between exclusive breastfeeding and stunting or underweight was unsurprising in this context; both stunting and underweight are lower than wasting in the $0-6$ month age group and increase later in infancy ${ }^{(2)}$ - this pattern is seen in the Bangladesh DHS data as well. Thus, it is not anticipated that the data would reveal associations between exclusive breastfeeding and stunting or underweight in the 0-6 month age range. However, emerging research findings suggest that early wasting is predictive of later stunting ${ }^{(49)}$ and thus the protective role for exclusive breast-feeding in relation to wasting takes on even greater public health significance, given the extremely high levels of stunting in Bangladesh and indeed South Asia.

It is well established that 6-23 months of age is a vulnerable period for child growth ${ }^{(2)}$. It is also a vulnerable period for IYCF practices, as this is the age range within which a child must effectively be transitioned from breast milk only to a combination of breast milk and nutritionally adequate complementary foods or 'family foods'. The analyses reported herein indicated that better IYCF practices during this vulnerable period were predictive of better growth outcomes among children. Our findings suggested adequate dietary diversity to be the indicator most strongly associated with better nutrition outcomes during this period. Other studies that have used a variety of indicators aimed at capturing food variety or dietary diversity have come to similar conclusions about the importance of the diversity of young children's $\operatorname{diets}^{(10,12,35,37,39-41)}$. Building on these previous studies, and using nationally representative data, our analysis also showed a clear association between dietary diversity and 
Table 3 Linear regression results for the association between DDI and HAZ in children aged 6-23 months, 2007 Bangladesh Demographic and Health Survey

\begin{tabular}{|c|c|c|}
\hline Independent variable & Coefficient & $t$ Statistic \\
\hline Child age (months) & -0.04 & $-0 \cdot 70$ \\
\hline Child age (squared) & 0.00 & -0.58 \\
\hline Child sex (reference: male) & -0.05 & -0.72 \\
\hline Material height $(\mathrm{cm})$ & $0.07^{\star \star \star}$ & $9 \cdot 04$ \\
\hline Maternal BMI & $0 \cdot 03^{(\star)}$ & $1 \cdot 86$ \\
\hline \multicolumn{3}{|l|}{ Maternal education } \\
\hline Primary v. none & $-0 \cdot 18$ & $-1 \cdot 49$ \\
\hline Secondary $v$. none & $-0 \cdot 11$ & $-0 \cdot 91$ \\
\hline \multicolumn{3}{|l|}{ Prenatal care visits } \\
\hline $1-3 v$. none & 0.08 & 0.94 \\
\hline$\geq 4 \mathrm{v}$. none & $0 \cdot 28^{*}$ & $2 \cdot 21$ \\
\hline \multicolumn{3}{|l|}{ Wealth index factors } \\
\hline Poorer v. poorest & $0 \cdot 14$ & $1 \cdot 24$ \\
\hline Middle $v$. poorest & $0 \cdot 27^{*}$ & $2 \cdot 08$ \\
\hline Richer $v$. poorest & $0 \cdot 43^{\star \star}$ & $3 \cdot 06$ \\
\hline Richest $v$. poorest & $0 \cdot 75^{\star \star \star}$ & $4 \cdot 71$ \\
\hline Currently breast-fed & $-0 \cdot 28$ & $-1 \cdot 17$ \\
\hline Number of children & -0.03 & -0.69 \\
\hline Mother's age at first birth & -0.02 & \\
\hline Regional dummies & Yes & \\
\hline DDI (continuous) & $0 \cdot 08^{\star *}$ & $2 \cdot 76$ \\
\hline Constant & $-11 \cdot 21^{\star \star *}$ & $-8 \cdot 33$ \\
\hline$n$ & 1508 & \\
\hline
\end{tabular}

DDI, dietary diversity index; HAZ, height for age Z-score.

${ }^{(\star)} P<0.10,{ }^{\star} P<0.05,{ }^{\star \star} P<0.01,{ }^{\star \star \star} P<0.001$.

linear growth above and beyond known socio-economic, sociodemographic and regional influences on child nutrition in the Bangladeshi context. The effect sizes for the associations seen between achieving MDD and child growth outcomes were substantial and biologically meaningful. Reviews of efficacy trials that aimed to improve complementary feeding among children aged 6-12 months found that improvements in growth rates due to these interventions ranged from $0 \cdot 10$ to $0 \cdot 50 \mathrm{SD}^{(50)}$. The associations seen in our analyses fell well within this range.

The lack of association between certain IYCF practices and child anthropometry does not imply that these practices are not important for child growth. For instance, the lack of association between early initiation of breast-feeding and child growth is not an argument against the importance of this practice. The evidence for the role of early and exclusive breast-feeding from a neonatal mortality perspective is strong and unequivocal ${ }^{(51)}$. From the perspective of child growth, however, it is possible that this indicator acts mainly as a marker of better practices along a continuum of recommended optimal IYCF practices rather than as a direct marker of the nutrient quality of child diets. We note here that those variables that are indeed more direct markers of the nutrient quality of child diets, i.e. exclusive breastfeeding, diet diversity, minimum acceptable diet, appeared to demonstrate stronger associations with the child growth outcomes.

From a methodological perspective, the new IYCF indicators are designed to be used with population-level cross-sectional data based on the known biological significance of these practices either independently or in conjunction with other recommended IYCF practices on child growth. Acknowledging, however, that crosssectional data do not allow robust causal inferences related to the links between these indicators and child growth, we highlight the need for longitudinal studies that document IYCF practices at the critical age points for each practice and together provide a stronger evidence base for the importance of these practices and their indicators in relation to child growth outcomes in different contexts.

The present study is not without limitations. First, as mentioned above, the cross-sectional nature of the data limits our analyses to exploring associations rather than determining causality. Longitudinal data would be better suited for this line of inquiry. However, we address the limitations of using cross-sectional data through inclusion of a variety of variables to control for confounding and regional unobservables. Second, the ability to generalize our results to other developing countries is not possible with this single country study although our results are likely applicable to similar regions in South Asia, including parts of India, given similarities in the growth patterns of infants in the region and the gaps in IYCF practices.

\section{Conclusions}

The results presented herein speak to three important points in relation to the Bangladeshi context: (i) exclusive breast-feeding under 6 months is protective of wasting; (ii) dietary diversity and the overall adequacy of child diets in the 6-23 months period is important for linear growth outcomes; and (iii) the new IYCF indicators exhibit important associations with child growth in Bangladesh and should continue to be monitored at a nationally representative scale.

Our findings have significant implications for public health practice, both in programme design and evaluation and for future research in Bangladesh and South Asia. We conclude that strategies to improve IYCF practices, and particularly to increase exclusive breast-feeding and improve the diversity of complementary foods fed to infants, should be a high priority in programmes that aim to address undernutrition among infants and young children in this region.

\section{Acknowledgements}

This research received no specific grant from any funding agency in the public, commercial or not-for-profit sectors. A.Z. conducted the analyses and write-up as part of her Masters degree in Public Health thesis at Emory University. K.W. and P.M. were supported by their institutions. There are no conflicts of interest. A.Z. conceptualized 
and implemented the data analysis, wrote first drafts of the manuscript and edited subsequent drafts. K.W. reviewed and edited the manuscript drafts, and supported the MPH thesis on same topic for A.Z. P.M. conceptualized and supported the data analysis, and reviewed and edited the manuscript versions.

\section{References}

1. Black RE, Allen LH, Bhutta ZA et al. (2008) Maternal and child undernutrition: global and regional exposures and health consequences. Lancet 371, 243-260.

2. Victora CG, de Onis M, Hallal PC et al. (2010) Worldwide timing of growth faltering: revisiting implications for interventions. Pediatrics 125, e473-e480.

3. Pelletier D (2002) Toward a Common Understanding of Malnutrition: Assessing the Contributions of the UNICEF Framework. Washington, DC and New York: World Bank and UNICEF.

4. Dewey KG, Cohen RJ \& Rollins NC (2004) WHO technical background paper: feeding of nonbreastfed children from 6 to 24 months of age in developing countries. Food Nutr Bull 25, 377-402.

5. World Health Organization/Pan American Health Organization (2003) Guiding Principles for Complementary Feeding of the Breastfed Child. Washington, DC: PAHO.

6. World Health Organization (1991) Indicators for Assessing Breastfeeding Practices. Geneva: WHO.

7. Working Group on Infant and Young Child Feeding Indicators (2006) Developing and Validating Simple Indicators of Dietary Quality and Energy Intake of Infants and Young Children in Developing Countries: Summary of Findings from Analysis of 10 Data Sets. Washington, DC: Food and Nutrition Technical Assistance Project, Academy for Educational Development.

8. World Health Organization/UNICEF (2008) Indicators for Assessing Infant and Young Child Feeding Practices: Conclusions of a Consensus Meeting held 6-8 November 2007 in Washington DC, USA. Geneva: WHO.

9. Arimond M, Daelmans B \& Dewey K (2008) Indicators for feeding practices in children. Lancet 371, 541-542.

10. Ruel MT \& Menon P (2002) Child feeding practices are associated with child nutritional status in Latin America: innovative uses of the demographic and health surveys. J Nutr 132, 1180-1187.

11. Ntab B, Simondon KB, Milet J et al. (2005) A young child feeding index is not associated with either height-for-age or height velocity in rural Senegalese children. J Nutr $\mathbf{1 3 5}$, 457-464.

12. Sawadogo PS, Martin-Prevel Y, Savy M et al. (2006) An infant and child feeding index is associated with the nutritional status of 6 - to 23 -month-old children in rural Burkina Faso. J Nutr 136, 656-663.

13. Garg A \& Chadha R (2009) Index for measuring the quality of complementary feeding practices in rural India. $J$ Health Popul Nutr 27, 763-771.

14. Moursi MM, Treche S, Martin-Prevel Y et al. (2009) Association of a summary index of child feeding with diet quality and growth of 6-23 months children in urban Madagascar. Eur J Clin Nutr 63, 718-724.

15. Zhang J, Shi L, Wang J et al. (2009) An infant and child feeding index is associated with child nutritional status in rural China. Early Hum Dev 85, 247-252.

16. Saha KK, Frongillo EA, Alam DS et al. (2008) Appropriate infant feeding practices result in better growth of infants and young children in rural Bangladesh. Am J Clin Nutr 87, 1852-1859.
17. Giashuddin MS, Kabir M, Rahman A et al. (2003) Exclusive breastfeeding and nutritional status in Bangladesh. Indian J Pediatr 70, 471-475.

18. Arifeen SE, Black RE, Caulfield LE et al. (2001) Determinants of infant growth in the slums of Dhaka: size and maturity at birth, breastfeeding and morbidity. Eur J Clin Nutr 55, 167-178.

19. Kalanda BF, Verhoeff FH \& Brabin BJ (2006) Breast and complementary feeding practices in relation to morbidity and growth in Malawian infants. Eur J Clin Nutr 60, 401-407.

20. Victora CG, Morris SS, Barros FC et al. (1998) Breast-feeding and growth in Brazilian infants. Am J Clin Nutr 67, 452-458.

21. Spyrides MH, Struchiner CJ, Barbosa MT et al. (2008) Effect of predominant breastfeeding duration on infant growth: a prospective study using nonlinear mixed effect models. J Pediatr (Rio J) 84, 237-243.

22. Alvarado BE, Zunzunegui MV, Delisle H et al. (2005) Growth trajectories are influenced by breast-feeding and infant health in an Afro-Colombian community. J Nutr 135, 2171-2178.

23. Gokcay G, Turan JM, Partalci A et al. (2003) Growth of infants during the first year of life according to feeding regimen in the first 4 months. $J$ Trop Pediatr 49, 6-12.

24. Simondon KB, Simondon F, Costes R et al. (2001) Breastfeeding is associated with improved growth in length, but not weight, in rural Senegalese toddlers. Am J Clin Nutr 73, 959-967.

25. Eckhardt CL, Rivera J, Adair LS et al. (2001) Full breastfeeding for at least four months has differential effects on growth before and after six months of age among children in a Mexican community. J Nutr 131, 2304-2309.

26. Villalpando S \& Lopez-Alarcon M (2000) Growth faltering is prevented by breast-feeding in underprivileged infants from Mexico City. J Nutr 130, 546-552.

27. Espo M, Kulmala T, Maleta K et al. (2002) Determinants of linear growth and predictors of severe stunting during infancy in rural Malawi. Acta Paediatr 91, 1364-1370.

28. Hop LT, Gross R, Giay T et al. (2000) Premature complementary feeding is associated with poorer growth of Vietnamese children. J Nutr 130, 2683-2690.

29. Galler JR, Ramsey FC, Harrison RH et al. (1998) Infant feeding practices in Barbados predict later growth. $J$ Nutr 128, 1328-1335.

30. Simondon KB \& Simondon F (1997) Age at introduction of complementary food and physical growth from 2 to 9 months in rural Senegal. Eur J Clin Nutr 51, 703-707.

31. Kant AK (1996) Indexes of overall diet quality: a review. J Am Diet Assoc 96, 785-791.

32. Kant AK (2004) Dietary patterns and health outcomes. J Am Diet Assoc 104, 615-635.

33. Ruel MT (2003) Operationalizing dietary diversity: a review of measurement issues and research priorities. J Nutr 133, 11 Suppl. 2, 3911S-3926S.

34. Hatloy A, Torheim LE \& Oshaug A (1998) Food variety a good indicator of nutritional adequacy of the diet? A case study from an urban area in Mali, West Africa. Eur J Clin Nutr 52, 891-898.

35. Onyango AW (2003) Dietary diversity, child nutrition and health in contemporary African communities. Comp Biochem Physiol A Mol Integr Physiol 136, 61-69.

36. Hoddinott J \& Yisehac Y (2002) Dietary Diversity as a Household Food Security Indicator. Washington, DC: Food and Nutrition Technical Assistance Project, Academy for Educational Development.

37. Arimond M \& Ruel MT (2004) Dietary diversity is associated with child nutritional status: evidence from 11 demographic and health surveys. J Nutr 134, 2579-2585.

38. Rah JH, Akhter N, Semba RD et al. (2010) Low dietary diversity is a predictor of child stunting in rural Bangladesh. Eur J Clin Nutr 64, 1393-1398. 
39. Onyango A, Koski KG \& Tucker KL (1998) Food diversity versus breastfeeding choice in determining anthropometric status in rural Kenyan toddlers. Int J Epidemiol 27, 484-489.

40. Allen L, Black A, Backstrand J et al. (1991) An analytical approach for exploring the importance of dietary quality versus quantity in the growth of Mexican children. Food Nutr Bull 13, 95-104.

41. Hatloy A, Hallund J, Diarra MM et al. (2000) Food variety, socioeconomic status and nutritional status in urban and rural areas in Koutiala (Mali). Public Health Nutr 3, 57-65.

42. National Institute of Population Research and Training, Mitra and Associates \& Macro International (2009) Bangladesh Demographic and Health Survey 2007. Dhaka and Calverton, MD: National Institute of Population Research and Training/ Mitra and Associates and Macro International.

43. World Health Organization (2010) The WHO Child Growth Standards. Geneva: WHO.

44. Measure DHS (2010) Demographic and Health Surveys. Methodology: The Wealth Index. http://www.measuredhs. com/topics/Wealth-and-Socioeconomics.cfm (accessed November 2011).

45. Arifeen S, Black RE, Antelman G et al. (2001) Exclusive breastfeeding reduces acute respiratory infection and diarrhea deaths among infants in Dhaka slums. Pediatrics 108, E67.
46. Kramer MS \& Kakuma R (2004) The optimal duration of exclusive breastfeeding: a systematic review. Adv Exp Med Biol 554, 63-77.

47. World Health Organization (1998) Complementary Feeding of Young Children In Developing Countries: A Review of Current Scientific Knowledge. WHO/NUT/981. Geneva: WHO.

48. Arnold F, Parasuraman S, Arokiasamy P et al. (2009) Nutrition in India. National Family Health Survey (NFHS-3), India, 2005-06. Mumbai and Calverton, MD: International Institute for Population Sciences and ICF Macro.

49. Menon P \& Stoltzfus RJ (2012) Building convergence in science, programs and policy actions on child undernutrition: symposium rationale and overview. Adv Nutr 3, 224-226.

50. Caulfield L, Huffman S \& Piwoz E (1999) Interventions to improve intake of complementary foods by infants 6 to 12 months of age in developing countries: impact on growth and on the prevalence of malnutrition and potential contribution to child survival. Food Nutr Bull 20, 183-200.

51. Bhutta ZA, Darmstadt GL, Hasan BS et al. (2005) Community-based interventions for improving perinatal and neonatal health outcomes in developing countries: a review of the evidence. Pediatrics 115, 519-617. 